\title{
INVESTIGATION OF EFFECT OF PROCESS PARAMETERS ON MICROHARDNESS IN FRICTION STIR WELDED DISSIMILAR ALUMINIUM ALLOYS AA2014-T651 AND
}

AA7075-T651

\begin{tabular}{|c|c|}
\hline $\begin{array}{l}\text { Sarpreet Singh* } \\
\text { Department of Mechanical Engineering, } \\
\text { D.A.V.I.E.T. Jalandhar } \\
\text { sarpreet.bal@gmail.com, }\end{array}$ & $\begin{array}{c}\text { Gaurav Kumar Dhuria } \\
\text { Department of Mechanical Engineering, } \\
\text { D.A.V.I.E.T. Jalandhar } \\
\text { gkdhuria@gmail.com }\end{array}$ \\
\hline
\end{tabular}

\begin{abstract}
Joints fabricated between dissimilar $2 \times x x$ and $7 \times x x$ aluminium alloys are need of hour in manufacturing various light weight aerospace and defense structures. The main motive of present study is to study the feasibility of friction stir welding of dissimilar aluminium alloys Al-Cu alloy AA2014-T651 and Al-Zn alloy AA7075-T651 which are difficult to weld using fusion welding processes. Defect free joints were fabricated in accordance with Taguchi's L9 orthogonal array on plates of AA7075-T651 and AA2014-T651 having $6.35 \mathrm{~mm}$ thickness. The influence of process parameters (welding speed, rotational speed and tool material) on microhardness distribution was investigated in detail and presented in graphical and tabular form for assistance in understanding. Nine experiments were performed at welding speed $(40,60$ and $80 \mathrm{~mm} / \mathrm{min})$ and rotational speed $(900,1200$ and $1500 \mathrm{rpm})$ using three different tool materials (HSS, H13 and SS-304). The results were analyzed using ANOVA which showed the significance of each process parameter. It was observed that tool material is the most significant factor and have percent contribution more than the combined contribution of welding speed and tool rotational speed.
\end{abstract}

Keywords: Friction stir welding, ANOVA, microhardness, AA2014-T651, AA7075-T651

\section{INTRODUCTION}

Friction Stir Welding (FSW), was invented as a solid state welding technique at TWI (The Welding Institute), Cambridge in 1991[1]. Aluminium alloys are very difficult to weld using fusion welding processes specially alloys of 2xxx and 7xxx series as aluminium shows great affinity to oxygen which results in formation of porosity and slag thus reduces the weld strength. The introduction of FSW opened doors for a new technology for welding those aluminium alloys which were considered un-weldable [2]. In FSW, the joints are fabricated at a lower temperature much below the melting temperature of alloys thus formation of oxides can be eliminated which otherwise will lead to sharp reduction in mechanical properties like tensile strength and microhardness [3]. Aluminium alloys AA2014 and AA7075 find application in shipping, defense and aerospace sectors because of high strength to weight ratio. In these sectors, the main emphasis is on weight reduction and FSW can be considered as an alternative of fasteners which will ultimately reduce the weight of structures [4, 5]. Avinash et al [6] observed a greater hardness in TMAZ compared to stir zone in FSW joints of AA2024 T3 and AA7075 T6. This variation was due to formation of coarse precipitates which were formed during precipitated hardening of base materials. Song et al [7] lap welded two combinations AA2024 and AA7075 and observed a maximum Vickers hardness of $140 \mathrm{HV}$ in AA2024 and 115 $\mathrm{HV}$ in AA7075. Lower hardness was obtained in the stir zone because of presence of voids. Sadeep et al [8] used cylindrical threaded, square, cylindrical, taper and stepped pin for welding dissimilar aluminium alloys AA2024 and AA6061. The microhardness of joints fabricated with square pin was 135.6 HV and with cylindrical threaded pin was $105.15 \mathrm{HV}$. It was observed that micro hardness in stir zone was less than base material AA2024 but greater than base material AA6061. Hariri et al [9] observed finest grain size in stir zone due to highly intense deformation in this region. Thermo-mechanical heat affected zone (TMAZ) undergoes plastic deformation but deformation strains were insufficient to recrystallise the grains in this region. Higher values of Vickers hardness were observed in stir zone. Koilraj et al [10] welded AA2219 to AA5083 and investigated that weld nugget is dominated by AA2219 placed on advancing side. A noticeable drop in hardness from unaffected material toward stir zone was observed. Whereas, hardness goes on increasing from base material AA5083 toward weld nugget boundary. Lowers hardness was observed in HAZ of AA5083 at retreating side where failure takes place during tensile testing. Ilangovan et al [11] studied the effect of process parameters in friction stir welding of AA6061 and AA5086 aluminium alloys and noticed a decrease in hardness from heat affected zone (HAZ) toward thermo-mechanically affected zone (TMAZ) and this region was noted as the softest region in the weld. Higher values of microhardness were observed in stir zone compared to HAZ and TMAZ. Rafi et al [12] observed significant drop in hardness zone in HAZ and TMAZ on both advancing side and retreating sides of friction stir welded AA7075 aluminium alloy joints. This drop in hardness was explained on the basis of strengthening particle $\mathrm{Mg} 2 \mathrm{Zn}$ and $\mathrm{Al} 2 \mathrm{CuMg}$. During welding both HAZ and TMAZ experience high temperature which leads to coarsening of these strengthening particles thus ultimately leading to lower hardness in these regions.

From the open literature it was observed that very scarce work has been reported on friction stir welding of AA2014 and AA7075 dissimilar aluminium alloys. This paper discuss the effect of process parameters such as welding speed, rotational speed and tool material on microhardness of friction stir fabricated dissimilar aluminium alloys AA2014 and AA7075.

\section{EXPERIMENTAL PROCEDURE}

The experiments were conducted on a vertical milling machine. The base materials used in this study are $6.35 \mathrm{~mm}$ thick plates of dissimilar aluminium alloys AA2014-T651 and AA7075-T651. The plates are cut in rectangular shape measuring $150 \mathrm{~mm} \times 75 \mathrm{~mm}$. The chemical compositions and 
mechanical properties of base materials are given in table 1 and table 2 .

Table 1 Chemical composition of base materials

\begin{tabular}{|c|c|c|c|c|c|c|c|c|}
\hline Material & $\mathrm{Cr}$ & $\mathrm{Cu}$ & $\mathrm{Fe}$ & $\mathrm{Mg}$ & $\mathrm{Mn}$ & $\mathrm{Si}$ & $\mathrm{Zn}$ & $\mathrm{Al}$ \\
\hline $\begin{array}{c}\text { AA2014- } \\
\text { T651 }\end{array}$ & 0.1 & 4.3 & 0.4 & 0.75 & 0.7 & 0.9 & 0.25 & 92.6 \\
\hline $\begin{array}{c}\text { AA7075- } \\
\text { T651 }\end{array}$ & 0.25 & 1.5 & 0.35 & 2.2 & 0.15 & 0.25 & 5.6 & 89.7 \\
\hline
\end{tabular}

Table 2 Mechanical properties of base materials

\begin{tabular}{|c|c|c|c|}
\hline $\begin{array}{c}\text { Base } \\
\text { Material }\end{array}$ & $\begin{array}{c}\text { Yield Strength } \\
(\mathrm{MPa})\end{array}$ & $\begin{array}{c}\text { Tensile strength } \\
(\mathrm{MPa})\end{array}$ & Hardness, HV \\
\hline $\begin{array}{c}\text { AA2014- } \\
\text { T651 }\end{array}$ & 414 & 483 & 150 \\
\hline $\begin{array}{c}\text { AA7075- } \\
\text { T651 }\end{array}$ & 503 & 572 & 165 \\
\hline
\end{tabular}

The process was carried out with AA2014 on advancing side and AA7075 on retreating side. The joints were fabricated with three different tools of HSS, H13 and SS-304 materials. The tools were having flat shoulder with $16 \mathrm{~mm}$ diameter. A hexagonal pin profile with $6.1 \mathrm{~mm}$ length and $6 \mathrm{~mm}$ pin diagonal length was used for all tool materials. The plates were placed on a backing bar and adequately clamped to avoid any slippage of plates during process. The experimental setup and clamping arrangement are shown in

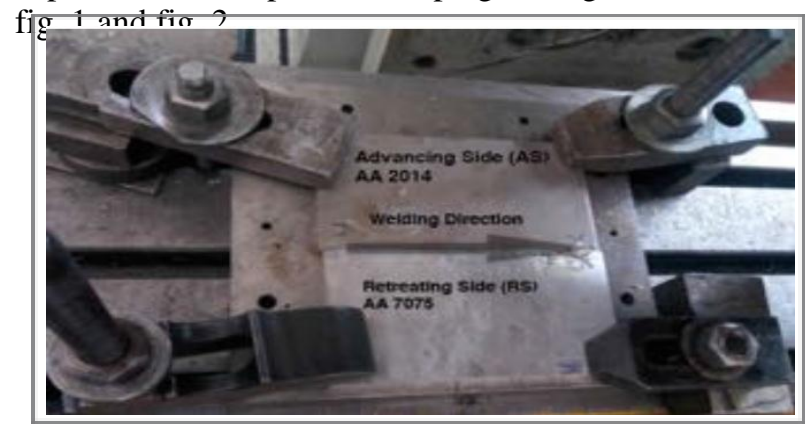

Fig. 1 Experimental Setup

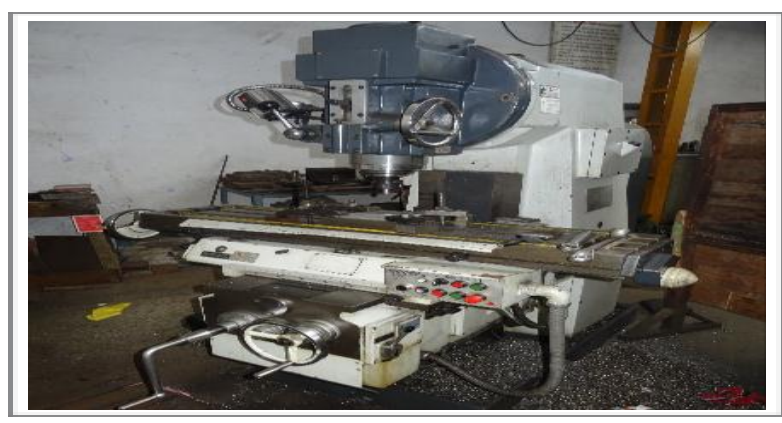

Fig. 2 Clamping Arrangement

Experiments were designed using Taguchi's L9 orthogonal array. The process parameters selected for present study were welding speed, rotational speed and tool materials.
The process was conducted at welding speeds of 40, 60 and 80 $\mathrm{mm} / \mathrm{min}$. The rotational speeds were kept 900, 1200 and 1500 $\mathrm{rpm}$. A tool tilt angle of $2^{0}$ is kept as fixed. All the welding conditions are specified in table 3 .

Table 3 Welding conditions

\begin{tabular}{|c|c|c|c|}
\hline S. No & $\begin{array}{c}\text { Rotational } \\
\text { Speed, rpm }\end{array}$ & $\begin{array}{c}\text { Welding Speed, } \\
\mathrm{mm} / \mathrm{min}\end{array}$ & Tool Material \\
\hline 1 & 900 & 40 & $\mathrm{HSS}$ \\
\hline 2 & 900 & 60 & $\mathrm{SS}$ \\
\hline 3 & 900 & 80 & $\mathrm{H} 13$ \\
\hline 4 & 1200 & 40 & $\mathrm{SS}$ \\
\hline 5 & 1200 & 60 & $\mathrm{H} 13$ \\
\hline 6 & 1200 & 80 & $\mathrm{HSS}$ \\
\hline 7 & 1500 & 40 & $\mathrm{H} 13$ \\
\hline 8 & 1500 & 60 & $\mathrm{HSS}$ \\
\hline 9 & 1500 & 80 & $\mathrm{SS}$ \\
\hline
\end{tabular}

Samples for microhardness were taken in the direction perpendicular to the weld for all experiments. All the samples were polished using various grades of emery paper. A disc polishing machine with fine alumina powder was used for final polishing. The hardness examination was carried out at three distinct levels moving from top to bottom surface of weld. Values of microhardness were taken at each level along the distance from the weld. Similarly, values of microhardness were taken at the top surface of the weld. Microhardness was tested under $50 \mathrm{~g}$ load for $10 \mathrm{sec}$.

\section{RESULTS AND DISCUSSIONS}

3.1 Variation of microhardness along thickness of joint Table 4 shows the variation of microhardness across various levels considered for investigation.

Table 4 Variation of hardness across thickness levels

\begin{tabular}{|c|c|c|c|c|c|c|c|}
\hline $\begin{array}{c}\text { S. } \\
\text { No }\end{array}$ & RS & WS & Tool & $\begin{array}{c}\text { Average } \\
\text { hardness } \\
\text { at upper } \\
\text { level }\end{array}$ & $\begin{array}{c}\text { Average } \\
\text { hardness } \\
\text { at middle } \\
\text { level }\end{array}$ & $\begin{array}{c}\text { Average } \\
\text { hardness } \\
\text { at lower } \\
\text { level }\end{array}$ & $\begin{array}{c}\text { Average } \\
\text { hardness } \\
\text { at top } \\
\text { surface }\end{array}$ \\
\hline 1 & 900 & 40 & HSS & 141.1 & 134.22 & 127.28 & 144.1 \\
\hline 2 & 900 & 60 & SS & 122.64 & 106.62 & 108.72 & 129.3 \\
\hline 3 & 900 & 80 & H13 & 135.22 & 128.56 & 121.82 & 137.5 \\
\hline 4 & 1200 & 40 & SS & 128.46 & 119.68 & 113.26 & 131.8 \\
\hline 5 & 1200 & 60 & H13 & 133.86 & 129.42 & 122.14 & 134.3 \\
\hline 6 & 1200 & 80 & HSS & 139.48 & 133.46 & 128.58 & 138.7 \\
\hline 7 & 1500 & 40 & H13 & 133.93 & 116.96 & 113.14 & 133.3 \\
\hline
\end{tabular}




\begin{tabular}{|c|c|c|c|c|c|c|c|}
\hline 8 & 1500 & 60 & HSS & 132.2 & 123.56 & 121.24 & 135.1 \\
\hline 9 & 1500 & 80 & SS & 129.46 & 127.3 & 126.6 & 121.9 \\
\hline
\end{tabular}

The hardness testing was performed in accordance with ASTM E92-82(2003) e2 standard, hardness values were measured starting from the centre toward left side (Advancing Side AA2014-T651) and right side (Retreating Side AA7075T651) of the weld along three different thickness levels viz. upper, middle and lower. Maximum values of hardness can be seen in the weld centre i.e. in stir zone. A gradual decrease in hardness was observed as we proceed from top to bottom surface of the weld and this variation was observed in all experiments. From fig. 3 it can be seen that there is a significant drop in microhardness in TMAZ and HAZ regions on both advancing and retreating side. The hardness values observed in TMAZ on retreating side are comparatively more than the values observed in advancing side. The reason for lower values of microhardness in HAZ and TMAZ can be explained on the basis of submicroscopic particles $\mathrm{Mg}_{2} \mathrm{Zn}$ and $\mathrm{Al}_{2} \mathrm{CuMg}$ which are mainly responsible for strength of base material. High temperature experienced in HAZ and TMAZ during friction stir welding process results in coarsening of these

strengthening particles thus leading to lower microhardness in these regions [12].

Table 5 Orthogonal array for $\mathrm{L9}$ with response (raw data and $\mathrm{S} / \mathrm{N}$ ratio)

\begin{tabular}{|c|c|c|c|c|c|}
\hline S. No & RS & WS & Tool & $\begin{array}{c}\text { Mean } \\
\text { Microhardness } \\
(H \mathrm{~V})\end{array}$ & S/N Ratio \\
\hline 1 & 900 & 40 & HSS & 144.1 & 42.1672 \\
\hline 2 & 900 & 60 & SS & 129.3 & 42.2118 \\
\hline 3 & 900 & 80 & H13 & 137.5 & 42.7344 \\
\hline 4 & 1200 & 40 & SS & 131.8 & 42.3454 \\
\hline 5 & 1200 & 60 & H13 & 134.3 & 42.5421 \\
\hline 6 & 1200 & 80 & HSS & 138.7 & 42.7976 \\
\hline 7 & 1500 & 40 & H13 & 133.3 & 42.2770 \\
\hline 8 & 1500 & 60 & HSS & 135.1 & 42.6067 \\
\hline 9 & 1500 & 80 & SS & 121.9 & 41.6557 \\
\hline
\end{tabular}

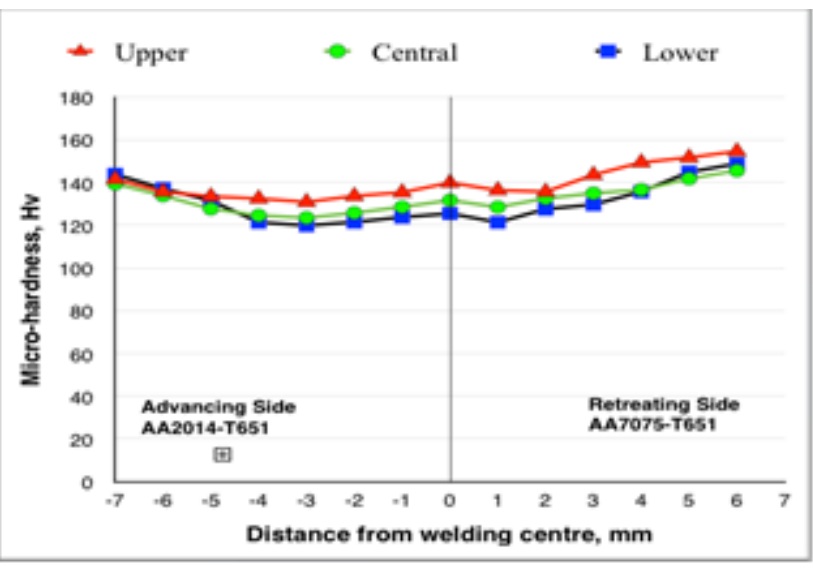

Fig. 3 Variation of microhardness along the distance from the weld

\subsection{Analysis of variance (ANOVA)}

ANOVA is a statistical technique used to identify the significance of individual process parameters. The purpose of ANOVA in this study is to investigate the process parameter which has significant effect on microhardness of friction stir welded joints. Signal-to-noise ratios $(\mathrm{S} / \mathrm{N})$ and means for all process parameters are calculated. In this investigation, tool material and tool rotational speed are highly significant factors and plays a vital role in affecting the microhardness.

For microhardness analysis, larger-the-better condition was chosen as microhardness of a welded specimen should be maximum for a given set of parameters. Hardness values taken at top surface of weld are used for analysis. The values of mean and signal to noise ratio are tabulated in table 6 and table 7.

The main effects plots for mean and $\mathrm{SN}$ ratio are plotted in fig. 4 and fig. 5. Predicted value of microhardness can be calculated using the observed values of responses for means at the best setting of process parameters.

Table 6 Analysis of Variance for Means

\begin{tabular}{|c|c|c|c|c|c|c|c|}
\hline Source & DF & $\begin{array}{c}\text { Seq. } \\
\text { SS }\end{array}$ & $\begin{array}{c}\text { Adj. } \\
\text { SS }\end{array}$ & $\begin{array}{c}\text { Adj. } \\
\text { MS }\end{array}$ & F & P & \% Contribution \\
\hline RS & 2 & 76.222 & 76.222 & 38.111 & 26.38 & $0.037^{*}$ & 23 \\
\hline WS & 2 & 27.556 & 27.556 & 13.778 & 9.54 & 0.095 & 9 \\
\hline Tool & 2 & 221.55 & 221.55 & 13.778 & 76.69 & $0.013^{*}$ & 67 \\
\hline $\begin{array}{c}\text { Residual } \\
\text { Error }\end{array}$ & 2 & 2.889 & 2.889 & 1.444 & & & 1 \\
\hline Total & 8 & 328.22 & & & & & 100 \\
\hline
\end{tabular}


Table 7 Analysis of Variance for signal to noise ratio

\begin{tabular}{|c|c|c|c|c|c|c|c|}
\hline Source & DF & $\begin{array}{l}\text { Seq. } \\
\text { SS }\end{array}$ & $\begin{array}{c}\text { Adj. } \\
\text { SS }\end{array}$ & $\begin{array}{c}\text { Adj. } \\
\text { MS }\end{array}$ & $F$ & $P$ & \% Contribution \\
\hline RS & 2 & 0.3295 & 0.3295 & 0.1647 & 18.76 & $0.051^{*}$ & 23 \\
\hline WS & 2 & 0.1187 & 0.1187 & 0.0593 & 6.76 & 0.129 & 8 \\
\hline Tool & 2 & 0.9561 & 0.9561 & 0.4780 & 54.43 & $0.018^{*}$ & 68 \\
\hline $\begin{array}{c}\text { Residual } \\
\text { Error }\end{array}$ & 2 & 0.0175 & 0.0175 & 0.0087 & & & 1 \\
\hline Total & 8 & 1.4220 & & & & & \\
\hline
\end{tabular}

* significant

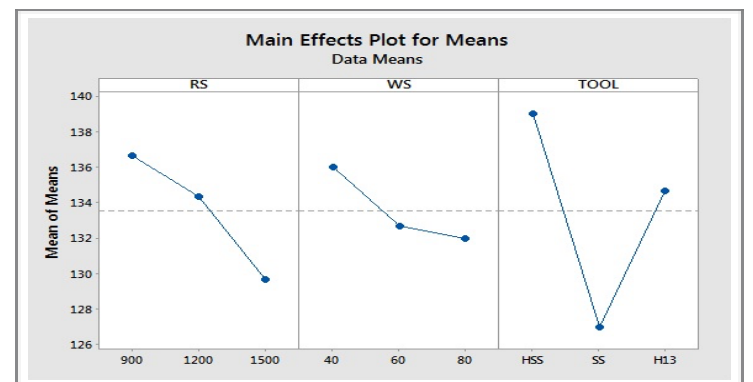

Fig. 4 Main effect plot for mean

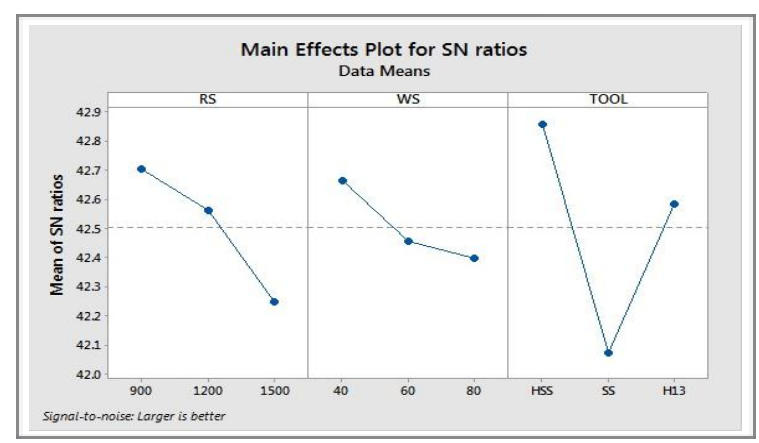

Microhardness (Predicted)

$=\mathrm{RS}_{1}+\mathrm{WS}_{1}+\mathrm{Tool}_{1}-2 \mathrm{H}$

$=136.7+136+139-2(133.56)=144.6 \mathrm{HV}$ where $\mathrm{RS}_{1}$ is the average mean value of rotational speed at $1 \mathrm{st}$ level. $\mathrm{WS}_{1}$ is the average mean value of welding speed at 1 st level. Tool ${ }_{1}$ is the average mean value of tool at 1 st level. $\mathrm{H}$ is the average value of hardness for all experiments.

The optimal process parameters thus obtained are rotational speed of $900 \mathrm{rpm}$, welding speed of $40 \mathrm{~mm} / \mathrm{min}$ and a HSS tool. An experiment was conducted at these parameters and average value of microhardness for friction stir welded AA2014-T651 and AA7075-T651 was 144.1HV.

\section{CONCLUSIONS}

The defect free joints of Al-Cu alloy AA2014-T651 and Al-Zn alloy AA7075-T651 were successfully fabricated using friction stir welding process. Process parameters were optimized for microhardness and optimum setting of process parameters was obtained. The optimum setting of tool material, welding speed and rotational speed thus obtained were HSS tool, $40 \mathrm{~mm} / \mathrm{min}$ and $900 \mathrm{rpm}$. At $95 \%$ confidence level, tool material and tool rotational speed were significant parameters and welding speed was comparatively less significant. Tool material contributes to $68 \%$ of total contribution and combined contribution of tool rotational speed and welding speed were $31 \%$. Hardness of the joint varied from top surface of weld toward bottom of joints and this variation was observed in all experiments. Also, hardness showed variation toward both advancing and retreating sides of joint. Lowest values of hardness were noted in HAZ and TMAZ region of AA2014-T651 alloy placed on advancing side.

\section{References}

[1] W. M. Thomas, E. D. Nicholas, J.C. Needham, M. G. Murch, P. Temple Smith and C. J. Dawes, G. B. Patent Application No.9125978.8 (December 1991).

[2] G. Pouget and A. P. Reynolds, "Residual stress and microstructure effects on fatigue crack growth inAA2050 friction stir weld", International Journal of Fatigue 30 (2008), pp. 463-472.

[3] Y. Li, L. E. Murr L and J. C. McClure, "Flow visualization residual microstructures associated with the friction-stir welding of 2024 aluminum to 6061aluminum”, Mater Sci Eng.,1999; pp. 213-223.

[4] R.John, K.V. Jata and K. Sadananda, "Residual stress effects on near threshold fatigue crack growth in friction stir welded aerospace alloys", International Journal of Fatigue 25(2003), pp. 939-948.

[5] M. Guerra, C. Schmidt, J.C. McClure, L.E. Murr and A.C. Nunes, "Flow patterns during friction stir welding", Materials Characterization49 (2003), pp. 95-101.

[6] P. Avinash, M. Manikandn, N. Arivazhagan, K. Devendranath Ramkumar and S. Narayanan, "Friction stir welded butt joints of AA2024 T3 and AA7075 T6 aluminum alloys", Procedia Engineering 75 (2014), pp. $98-102$.

[7] Youbao Song, Xinqi Yang, Lei Cui, Xiaopeng Hou, Zhikang Shen and Yan $\mathrm{Xu}$, "Defect features and mechanical properties of friction stir lap weldeddissimilar AA2024-AA7075 aluminum alloy sheets", Materials and Design 55 (2014), pp. 9-18.

[8] P. Sadeesh, M. Venkatesh Kannan, V. Rajkumar, P. Avinash, N. Arivazhagan, K. Devendranath Ramkumar and S. Narayanan, Studies on friction stir welding of AA 2024 and AA 6061 dissimilar metals", 7th International conference on materials for advanced technology, MRS Singapore - ICMAT Symposia Proceedings, Procedia Engineering 75 ( 2014 ), pp. $145-149$. 
[9] B.H. Hariri, G.S. Shiri, Y. Yaghoubinezhad and M.M. Rahvard, “ The optimum combination of tool rotation rate and traveling speed for obtaining the preferable corrosion behavior and mechanical properties of friction stir welded AA5052 aluminum alloy", Materials and Design 50 (2013), pp. 620-634.

[10] M. Koilraj, B. Sundareswaran, S. Vijayan and S.R. Rao, "Friction stir welding of dissimilar aluminum alloys AA2219 to AA5083 Optimization of process parameters using Taguchi technique", Materials and Design 42 (2012), pp. 1-7.

[11] M. Ilangovan, R.S. Boopathya and V. Balasubramanian, "Effect of tool pin profile on microstructure and tensile properties of friction stir welded dissimilar AA 6061eAA 5086 aluminium alloy joints", Defense Technology 11 (2015), pp. 174-184.

[12] H. Rafi Khalid, J.D.G. Ram, G. Phani kumar and P.K. Rao, "Microstructure and tensile properties of friction welded aluminum alloy AA7075-T6", Materials and Design 31 (2010), pp.2375-2380. 